\title{
Improving the back surface field on an amorphous silicon carbide (a- SiC:H) thin film photocathode for solar water splitting
}

\author{
Paula Perez-Rodriguez ${ }^{*}[\mathrm{a}]$, Drialys Cardenas-Morcoso ${ }^{[\mathrm{b}]}$, Ibadillah A. Digdaya ${ }^{[\mathrm{c}]}$, Andrea Mangel \\ Raventos $^{[\mathrm{a}]}$, Paul Procel ${ }^{[\mathrm{a}]}$, Olindo Isabella ${ }^{[\mathrm{a}]}$, Sixto Gimenez ${ }^{[\mathrm{b}]^{* *}}$, Miro Zeman ${ }^{[\mathrm{a}]}$, Wilson A. Smith ${ }^{[\mathrm{c}]}$, Arno \\ H.M. Smets ${ }^{[a]}$
}

\begin{abstract}
Amorphous silicon carbide (a-SiC:H) is a promising material for photoelectrochemical (PEC) water splitting due to its relatively small bandgap energy and high chemical and optoelectrical stability. In this work, the effect of introducing a surface field on the semiconductor/electrolyte interface of a p/i structured photocathode has been studied. By introducing an n-doped nanocrystaline silicon oxide (nc-SiO $\mathrm{x}: \mathrm{H}$ ) layer into a p/i amorphous silicon carbide (a-SiC:H) photocathode, the photovoltage and photocurrent of the device can be significantly improved, reaching values higher than $0.8 \mathrm{~V}$. This results from enhancing the internal electric field of the photocathode, reducing the Shockley-Read-Hall (SRH) recombination at the crucial interfaces due to better charge carrier separation, and improving selective carrier collection at these interfaces. Finally, the photocurrent was further enhanced by tuning the absorber layer thickness, arriving at a thickness of $150 \mathrm{~nm}$, after which the current saturates to $10 \mathrm{~mA} \mathrm{~cm}^{-2}$ at $0 \mathrm{~V}$ vs. RHE in a KPH electrolyte at $\mathrm{pH} 4$
\end{abstract}

\section{Introduction}

The growing world energy demand and the depletion of fossil fuels require alternatives to the current energy system. Solar energy offers a cleaner and more sustainable alternative due to the high amount of solar energy availability and relatively easy installation and maintenance of solar systems. However, due to daily and seasonal fluctuations in irradiance, energy storage plays an important role in the implementation of solar energy. Daily irradiance variations can be tackled by using batteries, but seasonal variations need alternative storage methods that offer a cheaper and more energy dense solution [1]. Hydrogen is a plausible option to tackle this problem, since it can be easily stored in tanks or further converted into other hydrocarbons by using carbon dioxide $\left(\mathrm{CO}_{2}\right)$, which have a high energy density and low cost. Moreover, the resulting products can be stored for long periods of time with minimum losses such as self-discharge [2]. Direct hydrogen production using solar driven water splitting has attracted considerable attention in the last years [3] [4] [5] [6] [7] In particular, photoelectrochemical (PEC) devices provide a simple and elegant solution to hydrogen production using solar energy.

Photoelectrochemical production of hydrogen from water splitting is based on a material which absorbs light and generates electron-hole pairs. These charge carriers are then separated within the semiconductor and used to drive the two half-reactions at the cathode and anode, which produce highly pure hydrogen and oxygen on the electrode surfaces, respectively. There are several characteristics that a

[a] Photovoltaic Materials and Devices (PVMD) group, Delft University of Technology. Delft, The Netherlands

[b] Institute of Advanced Materials (INAM), Universitat Jaume I,12006 Castelló de la Plana, Spain

[c] Materials for Energy Storage and Conversion (MECS), Department of Chemical Engineering, Delft University of Technology. Delft, The Netherlands

Corresponding authors:

* p.perezrodriguez@tudelft.nl

**sjulia@fca.uii.es semiconductor needs to fulfil for its use in a PEC device: adequate optical properties, good charge separation, chemical stability, and correct band alignment with respect to the potentials of the water splitting reaction [7]. In addition, the materials used need to be earth-abundant in order to achieve a cost-effective solution. The PEC field has dedicated extensive effort to the search for a suitable material to drive the water splitting reaction. Among the thin-film semiconductors based on metal oxides tested for this application are $\mathrm{TiO}_{2}$ [8] , [9] [10], $\mathrm{Fe}_{2} \mathrm{O}_{3}$ [11] $,{ }^{[12]}, \mathrm{WO}_{3}{ }^{[13]}$ or $\mathrm{BiVO}_{4}{ }^{[14]}$. These semiconductors can produce relatively high photovoltages, due to their relatively large bandgap energy. However, they absorb only a small fraction of the solar spectrum. Therefore, there has recently been a shift to investigate non metal-oxide photolectrodes with smaller bandgap energies, such as silicon, which in theory could enhance the amount of photocurrent generation [15] [16] [17. Zhu et al. [18] proposed an amorphous silicon carbide (a-SiC:H) photocathode with a bandgap energy of $2.0 \mathrm{eV}$. Moreover, Han et al. ${ }^{[19]}$ introduced a gradient boron doped homojunction to improve the internal electric field and charge carrier collection. Thus, the attention has recently started to shift from material science towards device architecture design, using strategies such as the inclusion of different doped layers ${ }^{[3]}[1,[19],[20]$ and the introduction of a surface field at the semiconductor/electrolyte interface for a more selective charge carrier collection [21]. These results show that not only the material used as photoelectrode is important, but also the charge carrier separation and collection. Therefore, the optimization of internal electric fields can play an important role on the performance of PEC devices ${ }^{[22]}$.

In order to improve the charge carrier collection, the different electronic junctions formed in the device must be optimized ${ }^{[23]}$. If the interface contains many defects, Shockley-Read-Hall (SRH) recombination, also called defect-assisted charge carrier recombination, can occur at the junction. Homojunctions such as the (p)a-SiC:H/(i)a-SiC:H previously introduced lead to limited $\mathrm{SRH}$ recombination due to the reduced amount of defects such as dangling bonds or lattice mismatch at the interface. That is not the case with some other junctions like heterojunctions, semiconductor/metal or semiconductor/electrolyte junctions, where the differences between the material lattice, possible dangling bonds, voids and other defects can lead to higher levels of SRH recombination at the interface. To avoid this effect, an electric field and selective contacts can be introduced near the surface to screen away the minority charge carriers. This concept has already been successfully used for semiconductor/metal contacts in the photovoltaic (PV) field [24] [25]. The present study focuses on the improvement of an a-SiC: $\mathrm{H}$ photocathode by using the concepts developed in the photovoltaic (PV) field such as passivation of interfaces, selective contacts and electric fields by optimizing a back surface field. Here, the know-how of the PV field regarding the enhancement of the internal electric field and charge carrier collection is combined with the PEC expertise on the solar water splitting reaction, especially the hydrogen evolution reaction, to develop a more efficient PEC device. To improve the overall performance of a-SiC:H photocathode, the effect of introducing a back surface field by adding an n-doped nanocrystalline silicon oxide $\left(n c-\mathrm{SiO}_{x}: \mathrm{H}\right)$ layer to create a $\mathrm{p} / \mathrm{i} / \mathrm{n}$ structure was studied. The characteristics of $n c-\mathrm{SiO}_{x}: \mathrm{H}$ can be tuned depending on the oxygen content ${ }^{[26]}$, and therefore it is widely used as an n-layer 
for thin film silicon solar cells. This layer enhances the electric field created inside the semiconductor, which facilitates the charge carrier separation. In addition, it serves as a selective contact to improve charge carrier collection, and to passivate surface defects that can lead to $\mathrm{SRH}$ recombination. Furthermore, when an undoped $\mathrm{TiO}_{2}$ protective layer is introduced at the semiconductor/electrolyte interface, both the band alignment and chemical stability can be improved [27], [28] The general structure of the a-SiC:H photocathode with both the (n)nc-SiO$\times 1: H$ and the $\mathrm{TiO}_{2}$ layer is shown in Figure 1.

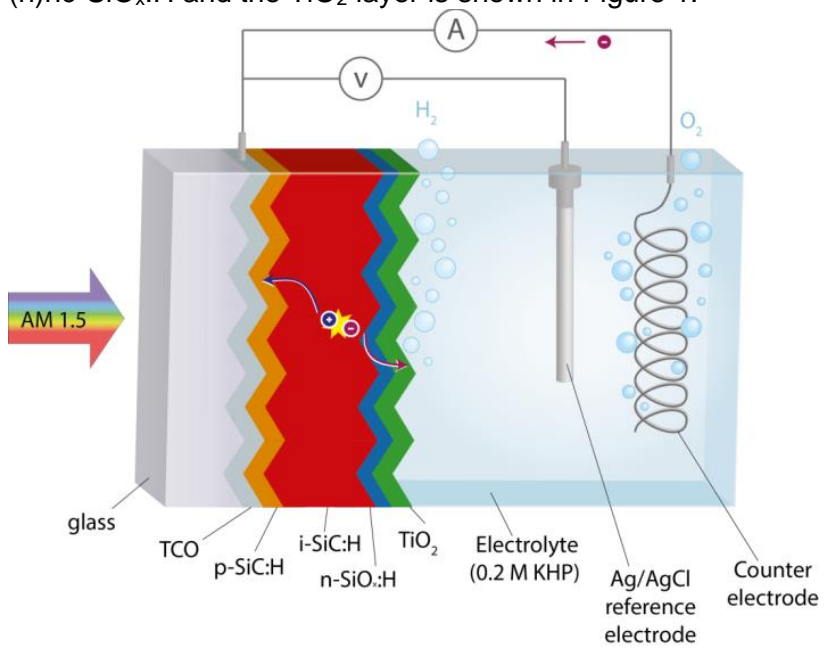

Figure 1. Schematic representation of the photoelectrochemical measurements carried out in a three-electrode configuration.

\section{Results and Discussion}

Including an n-layer on an amorphous silicon carbide (a-SiC:H) photocathode is expected to improve its performance due to a better charge carrier separation and collection, and a reduction in the $\mathrm{SRH}$ recombination. Previously, protective layers such as $\mathrm{TiO}_{2}$ have demonstrated not only to improve stability, but also to create a back surface field, improving the carrier injection at the semiconductor/electrolyte interface [29]. However, $\mathrm{TiO}_{2}$ has a relatively high density of states and a relatively high lattice mismatch with a-SiC: ${ }^{[27]}$. This causes recombination at the a$\mathrm{SiC}: \mathrm{H} / \mathrm{TiO}_{2}$ interface, and therefore limits the photoelectrode efficiency. In addition, the created electric field strength is low, since $\mathrm{TiO}^{2}$ has a relatively low donor density. Alternatively, a phosphorous doped nanocrystalline silicon oxide $\left((n) n c-S_{i O}: H\right)$ could be included in this structure. Phosphorous doped nanocrystalline silicon oxide, $(\mathrm{n}) \mathrm{nc}-\mathrm{SiO}_{\mathrm{x}}: \mathrm{H}$, is often used in thin film silicon solar cells as an n-layer to improve the internal electric field and charge carrier selectivity, in addition to its favourable optical properties $\stackrel{[26}{2}, \underline{30]}$. Thus, it is expected to improve the performance of the a-SiC:H photocathode.

Figure 2 shows the photoelectrochemical behaviour of different a-SiC:H photocathodes with and without a $(n) n c-S i O_{x}: H$ layer and with and without a $\mathrm{TiO}_{2}$ layer. These results show that the introduction of a back surface field, either by introducing an (n)nc-SiO $: \mathrm{H}$ or a naturally $\mathrm{n}$-type $\mathrm{TiO}_{2}$ layer, largely improves the onset potential of the photocathode from approximately -0.4 $\mathrm{V}$ vs. RHE to about 0.6-0.7 V vs. RHE. The photocathode with only the (n)nc-SiO :H layer has a slightly higher onset potential, but the one with only $\mathrm{TiO}_{2}$ presents a steeper JV slope,

indicating a lower series resistance, which suggests that the injection of charge carriers into the electrolyte is facilitated. This might be due to a better band alignment of the $\mathrm{TiO}_{2}$, which would reduce the resistance at the $\mathrm{TiO}_{2} /$ electrolyte interface. Finally, by combining both layers, the performance of the photocathode is further improved, resulting in onset potentials higher than $0.8 \mathrm{~V}$ vs. RHE, a steep slope indicating lower series resistances, and a current density of $10 \mathrm{~mA} / \mathrm{cm}^{2}$ at $0 \mathrm{~V}$ vs. RHE. This current density is comparable to other state-of-the-art devices, with current densities ranging between $8-12 \mathrm{~mA} / \mathrm{cm}^{2}$ for a-SiC:H photocathodes. This paper focuses on analysing the fundamental semiconductor physics associated with these high performances.

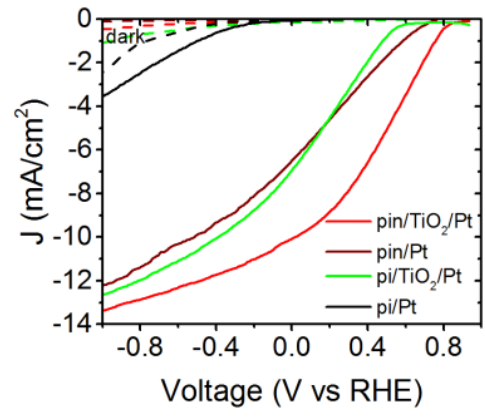

Figure 2. JV characteristics as a PEC device for the different samples with and without an n-layer, and with and without $\mathrm{TiO}_{2}$ in a three-electrode configuration.

In order to confirm the effect of the band alignment and reduced series resistance of the $(\mathrm{n}) \mathrm{nc}-\mathrm{SiO}_{\mathrm{x}}: \mathrm{H}$ and the $\mathrm{TiO}_{2}$ layer with the electrolyte, an EIS study at a range of frequencies $\left(10^{-1}-10^{5} \mathrm{~Hz}\right)$ has been performed to identity the most suitable frequency to carry out a single frequency Mott-Schottky analysis.. In this analysis, the capacitance is the depletion layer capacitance. Figure 3 shows the Mott-Schottky plots of the two materials in order to compare the band alignment effects of a $(n) n c-S i O_{x}: H$ and $\mathrm{a} \mathrm{TiO}_{2}$ layer in contact with the electrolyte ${ }^{[\underline{29}]}$.

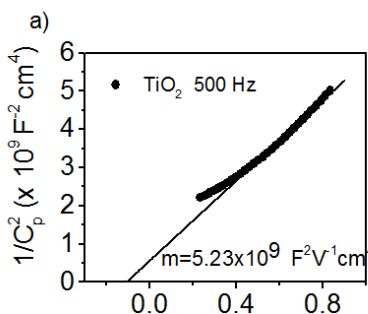

Potential (V vs. RHE)

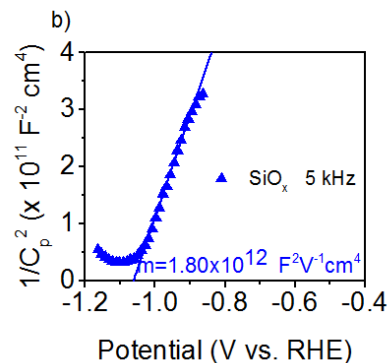

Figure 3. Mott-Schottky plots of a) a $100 \mathrm{~nm} \mathrm{TiO}_{2}$ layer, and b) a (n)nc-SiO $: \mathrm{H}$ layer with thickness of $100 \mathrm{~nm}$. The variable $\mathrm{m}$ indicates the slope of the fitted linear function

From the dark EIS measurements, the flat band potential of (n)nc-SiO $: \mathrm{H}, V_{f b}$, can be calculated by using the relation ${ }^{[31]}$

$$
\frac{1}{C^{2}}=\frac{2}{e \varepsilon_{0} \varepsilon_{r} N_{D}}\left(V-V_{f b}-\frac{k T}{e}\right)
$$

where $C$ represents capacitance, $e$ is the elementary charge, $\varepsilon_{0}$ is the permittivity in vacuum, $\varepsilon_{r}$ is the relative permittivity of the (n)nc-SiO $: \mathrm{H}, \quad k$ is the Boltzmann constant and $T$ is the temperature, taken as $298 \mathrm{~K}$. 
The flatband potential can be calculated from the intercept of the Mott-Schottky plot with the voltage-axis displayed in Figure 3, as

$$
\text { intercept voltage axis }=V_{f b}+\frac{k_{B} T}{e}
$$

The calculations resulted in a flatband potential of $-0.13 \mathrm{~V}$ vs. $\mathrm{RHE}$ for the $\mathrm{TiO}_{2}$ sample of $100 \mathrm{~nm}$, and $-1.06 \mathrm{~V}$ vs. RHE for the case of $100 \mathrm{~nm}(\mathrm{n}) \mathrm{nc}-\mathrm{SiO}_{\mathrm{x}}: \mathrm{H}$ samples. These values were used in further simulations of the different band diagrams in Sentaurus, as shown in Figure 4.
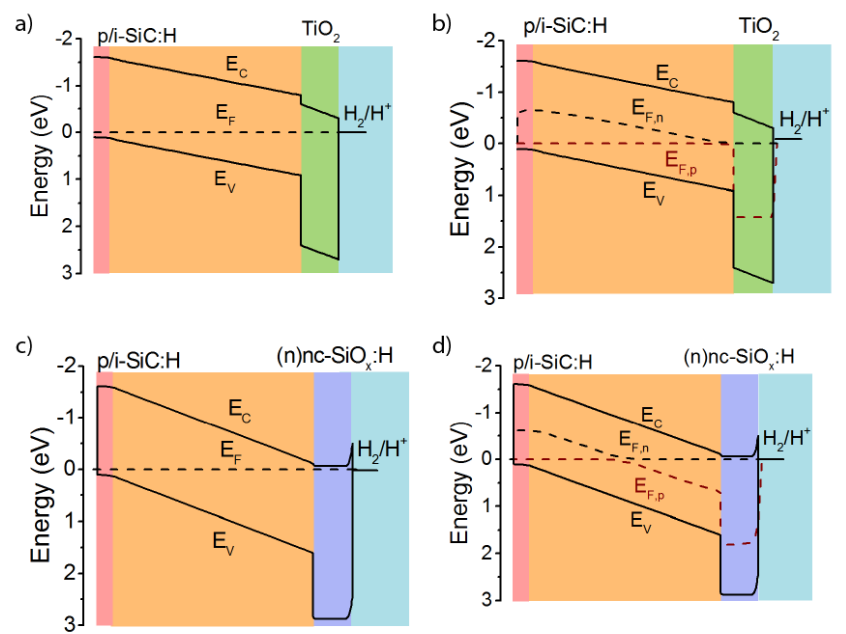

d)

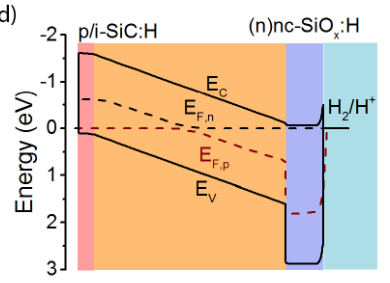

e) -2 pli-SiC:H (n)nc-SiO $: \mathrm{H}_{x} \mathrm{TiO}_{2}$
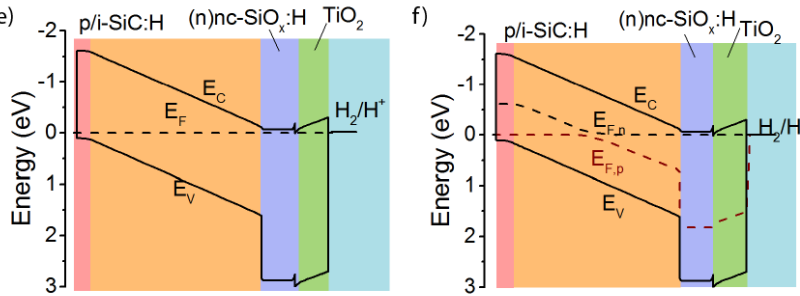

Figure 4. Simulations of the band alignment of the photocathode with respect to the solution with a p/i/n junction including a,b) $\left.\mathrm{TiO}_{2}, \mathrm{c}, \mathrm{d}\right) \mathrm{nc}-\mathrm{SiO}_{\mathrm{x}}: \mathrm{H}$ and $e, f)$ the combination of both in the dark $(a, c, e)$ and illuminated under one sun $(b, d, f)$

Since the donor density of $(\mathrm{n}) \mathrm{nc}-\mathrm{SiO}_{\mathrm{x}}: \mathrm{H}$ is expected to be larger compared to $\mathrm{TiO}_{2}$ due to the intentional doping introduced, the band alignment of (n)nc-SiO $: \mathrm{H}$ with the electrolyte is less optimal. This has been confirmed by determining the activation energy of the layers, which represents the difference between the conduction band and the Fermi energy level. This activation energy was determined by dark conductivity measurements of the isolated layers. An activation energy of $66.03 \mathrm{meV}$ was measured for $(\mathrm{n}) \mathrm{nc}-\mathrm{SiO}_{\mathrm{x}}: \mathrm{H}$, and $266.36 \mathrm{meV}$ for $\mathrm{TiO}_{2}$. This is also shown in the electrical simulations presented in Figure 4. The higher flat band potential of $(\mathrm{n}) \mathrm{nc}-\mathrm{SiO}_{\mathrm{x}}: \mathrm{H}$ suggests a higher band bending at the semiconductor/electrolyte interface, creating the energy barrier shown in Figure 4d), leading to charge recombination at the semiconductor/electrolyte interface. On the other hand, $\mathrm{TiO}_{2}$ has a better alignment with the solution, where the flatband potential is close to zero. This could explain the differences observed between the $\mathrm{p} / \mathrm{i} / \mathrm{n} / \mathrm{Pt}$ and the $\mathrm{p} / \mathrm{i} / \mathrm{TiO}_{2} / \mathrm{Pt}$ photocathodes. It must also be noted that the (n)nc-SiO $: \mathrm{H}$ samples were not stable in the solution, creating uncertainties in the measurement. It is thus possible that the flatband potentials of this material are even more negative, highlighting the benefits of adding a $\mathrm{TiO}_{2}$ layer on the surface. On the other hand, (n)nc-
$\mathrm{SiO}_{\mathrm{x}}: \mathrm{H}$ improves the internal electric field and charge carrier collection selectivity. If $\mathrm{TiO}_{2}$ is used at the surface of the (n)nc$\mathrm{SiO}_{\mathrm{x}}: \mathrm{H}$ samples, the energy barrier at the interface with the electrolyte is slightly reduced, as shown in Figure 4f), facilitating charge injection and reducing recombination. The $\mathrm{p} / \mathrm{i} / \mathrm{n} / \mathrm{TiO}_{2} / \mathrm{Pt}$ system outperforms the $\mathrm{p} / \mathrm{i} / \mathrm{TiO}_{2} / \mathrm{Pt}$ structure due to the effects on the interface between (i)a-SiC: $\mathrm{H}$ and $\mathrm{TiO}_{2}$, where the selectivity and electric field produced is not as strong as with the (n)nc-SiO $: \mathrm{H}$. Another factor that these simulations show is the creation of a small energy barrier at the (n)nc-SiO $: \mathrm{H}^{-\mathrm{TiO}}{ }_{2}$ interface due to the work function of these different layers. However, the disadvantage of this interface is overcome by the advantages of an improved internal electric field and band alignment.

To deconvolute the surface effects of this combination of layers, an EIS analysis was performed for the $(n) n c-S i O_{x}: H$ and $(n) n c-$ $\mathrm{SiO}_{x}: \mathrm{H} / \mathrm{TiO}_{2}$ samples, shown in Figure 5 . By fitting the resulting data to the Randles' equivalent circuit, resistances and capacitances at the semiconductor/electrolyte interface could be obtained. It can be seen that the resistance at the interface is higher for the case of the (n)nc-SiO $: \mathrm{H} / \mathrm{TiO}_{2}$ combination both in dark and illuminated conditions. This is probably caused by the additional resistances included by the $\mathrm{TiO}_{2}$ layer. This was confirmed by measuring the lateral conductivity of the layer at $25{ }^{\circ} \mathrm{C}$, which resulted in a value of $0.304 \mathrm{~S} / \mathrm{cm}$ for the (n)ncSiOx: $\mathrm{H}$ and $6.6010^{-5} \mathrm{~S} / \mathrm{cm}$ for the $\mathrm{TiO}_{2}$. Nevertheless, the reduction of the resistance upon illumination is higher when $\mathrm{TiO}_{2}$ is included due to a better charge carrier injection from the $\mathrm{SiOx}: \mathrm{H}$ layer into the electrolyte. Regarding the capacitance, both the (n)nc-SiO $: \mathrm{H}$ sample and (n)nc-SiO $: \mathrm{H} / \mathrm{TiO}$ combination show a fairly constant capacitance with voltage, and an increase when illuminated with respect to dark conditions. This suggests the that the double layer capacitance dominates the capacitive response of the electrode in both cases. The overall capacitance is however higher in the (n)nc-SiO $: H$ sample, which could stem from photocorrosion, which is limited in the other sample due to the protection provided by $\mathrm{TiO}_{2}$.

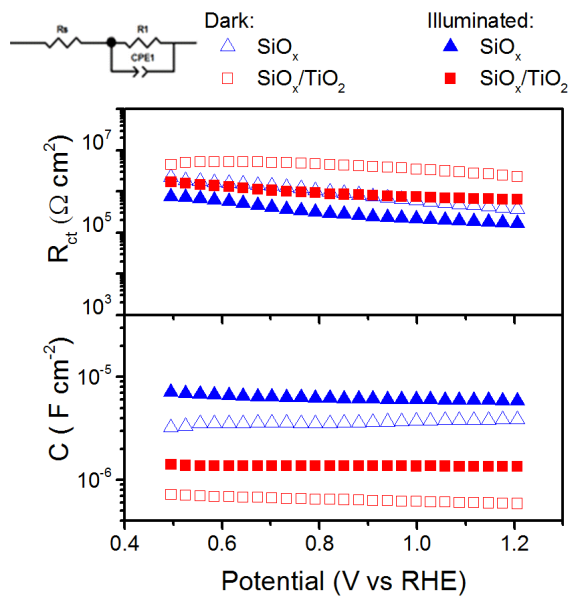

Figure 5. EIS analysis of a 100nm (n)nc-SiOx:H and a $100 \mathrm{~nm}(\mathrm{n}) \mathrm{nc}-\mathrm{SiOx}: \mathrm{H}$ $/ 20 \mathrm{~nm} \mathrm{TiO} 2$ film in dark conditions and under AM1.5 illumination (0.5M KHP $\mathrm{pH} 4$ ), together with the equivalent Randles' circuit including a Warburg element. Note that these measurements have been done for positive potentials, and thus under reverse bias.

To see if these trends can be extrapolated to the whole device, the same measurements were performed on $\mathrm{p} / \mathrm{i} / \mathrm{n}$ a-SiC: $\mathrm{H}$ samples, with and without a $\mathrm{TiO}_{2}$ layer, as shown in Figure 6. 
The impedance spectroscopy measurements carried out for this analysis did only show a single arc. This means that a single process is dominating the response of the system, although there are different processes taking place, which are invisible for impedance spectroscopy, probably because they appear at a time scale not sensitive for our experimental technique. We assigned the resistance to the charge transfer process, since it is extremely high to account for any other internal process in the multi-layered structure. Additionally, the constant evolution of the capacitance versus applied voltage is also an indication of a double layer dielectric capacitance, so it is reasonable to associate the elements of the Randles' circuit to the double layer capacitance and charge transfer resistance. The presence of a Warburg element in the equivalent circuit of Figure 6 accounts for the diffusion of electrolyte species, (see Supplementary Information, Figure SIX). The resistance shows less variation between dark and illuminated conditions compared to the results in Figure 5. The inclusion of the $\mathrm{TiO}_{2}$ layer in this case results in a lower resistance, probably due to the better band alignment and easier charge carrier injection. Regarding the capacitance, it increases with illumination in both cases, especially in the case of the sample with a $\mathrm{TiO}_{2}$ layer. However, it must be noted that these capacitances have been reduced by at least one order of magnitude as compared to the individual layers, indicating the benefit of having a $\mathrm{p} / \mathrm{i} / \mathrm{n}$ structure for charge carrier transfer at the interface.

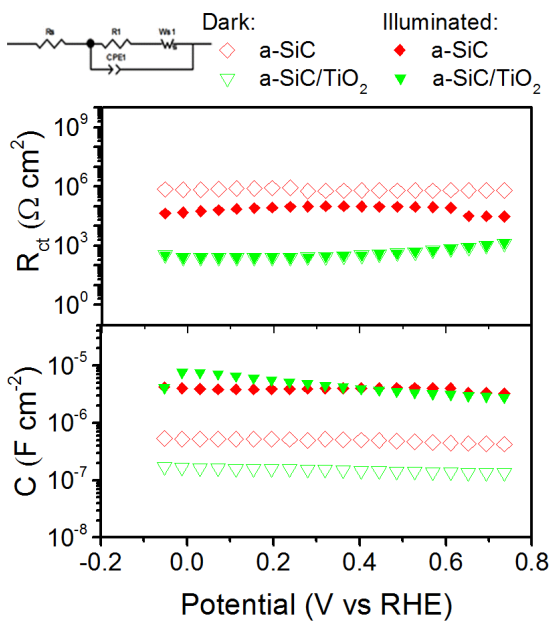

Figure 6. EIS analysis of a-SiC:H and a-SiC: $\mathrm{H} / \mathrm{TiO}_{2}$ samples in dark and under AM1.5 illumination conditions $(0.5 \mathrm{M} \mathrm{KHP} \mathrm{pH} 4)$, together with the equivalent Randles' circuit including a Warburg element, which accounts for the diffusion of electrolyte species. Note that these measurements have been done for positive potentials, and thus under reverse bias.

In summary, the introduction of a $\mathrm{TiO}_{2}$ layer improves the band alignment of the photocathode. Regarding the introduction of a (n)nc-SiO $\mathrm{x}: \mathrm{H}$ layer between the absorber material and the $\mathrm{TiO}_{2}$, it seems to achieve a lower defect density, lower $\mathrm{SRH}$ recombination and higher charge carrier selectivity and the internal electric field.

In order to further study the effects of the improvement of charge carrier separation and collection in the semiconductor, and the extraction of charge carriers at the semiconductor/electrolyte interface, the two considerations were decoupled. First, the semiconductor internal electric field and optical absorption in the absorber were studied by isolating the semiconductor device as a PV solar cell, where the charge carrier extraction is assumed not to be the limiting factor (Figure 7a, b). Second, to look at the effects of the catalyst and electrolyte, the electrochemical characteristics were measured (Figure 7c). The improvements in the internal electric field when introducing a (n)nc-SiO $\mathrm{x}: \mathrm{H}$ layer in the $\mathrm{p} / \mathrm{i}$ structure were confirmed for different $n$-layer thicknesses, as can be seen in Figure 7 and Table 1. The n-layer thickness can change the optical performance of the photoelectrode, as well as affecting possible tunnelling effects through this layer Moreover, if the layer is too thin, pinholes might appear creating short-circuit paths. When no n-layer is present, the open circuit voltage when measured as a solid-state PV junction is less than $0.4 \mathrm{~V}$. When a layer as thin as $10 \mathrm{~nm}$ is introduced, the open circuit voltage and short circuit current are drastically improved, reaching almost the same values as thicker layers. However, the fill factor in this case is very poor, probably due to inhomogeneities in the layer thickness that may cause areas without $n$-layer within the cell and possible tunnelling effects. A thickness of $20 \mathrm{~nm}$ for the $\mathrm{n}$-layer appears to be large enough for a good performance, reaching an open circuit voltage of 0.8 $V$ and short circuit current density of more than $10 \mathrm{~mA} / \mathrm{cm}^{2}$, with a fill factor of almost 0.6. Further increase of the n-layer thickness leads to a slight increase in the fill factor and short circuit current that could be related to the optical properties of nc-SiO ${ }_{x}$, which enhance the back reflection. ${ }^{[30}$, 32] Figure $7 \mathrm{~b}$ shows that when no n-layer is included, a big fraction of the light with wavelengths higher than $450 \mathrm{~nm}$ is not absorbed. The introduction of an n-layer as thin as $10 \mathrm{~nm}$ already improves these results. The optimum appears to be $30 \mathrm{~nm}$, especially due to a higher current density. However, this improvement is not so apparent in the PEC measurements in Figure 7c, where the differences of the saturation current densities are within measurement error. This difference could be caused by the absence of $\mathrm{Ag}$ back reflector when measuring PEC JV characteristics. In addition, it seems that the (n)nc-SiO $: \mathrm{H}$ thickness is not the limiting factor of the photocathode performance, as long as it is present. This can be seen in the onset potential in Figure 7c, where virtually no difference can be seen. Therefore, by ensuring that the semiconductor internal electric field effectively separates and collects the charge carriers, it is clear that the charge carrier injection into the electrolyte is the limiting factor of these devices. Finally, it is interesting to compare these onset-potentials $(0.78-0.81 \mathrm{~V})$ with the open circuit voltages of the solid-state measurements $(0.81$ $0.83 \mathrm{~V}$ ) when the thickness has reached the thickness of $20 \mathrm{~nm}$. There seems to be a negligible difference of around $20-30 \mathrm{mV}$ between these two measurements, which can be related to the dependence of the overpotentials on the charge carrier injection into the electrolyte and the catalytic effects at the semiconductor/electrolyte interface.
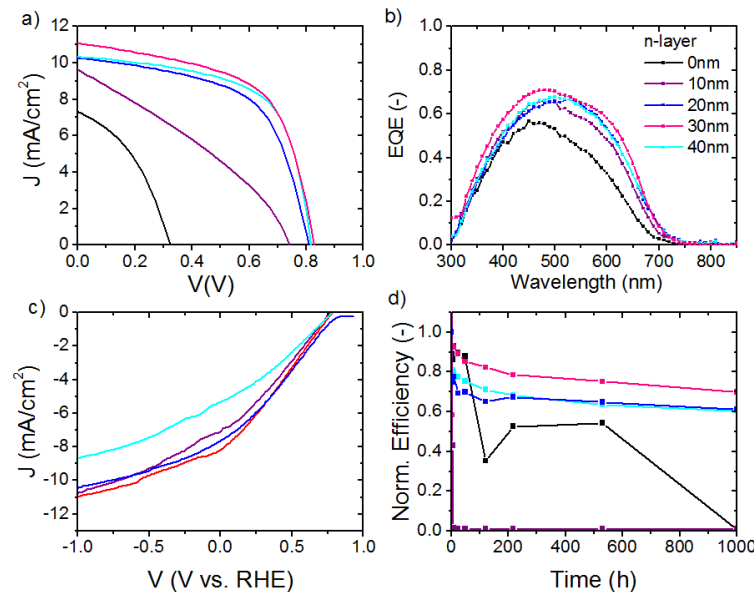
Figure 7. a) Solid state JV curves, b) EQE measurements, c) PEC JV curves and d) light-induced degradation $1000 \mathrm{~h}$ of the a-SiC: $\mathrm{H}$ photocathodes at different n-layer thicknesses including a $\mathrm{TiO}_{2}$ protective layer and a $\mathrm{Pt}$ catalyst.

Table 1. External parameters of the solid state JV characteristics with different n-layer thickness

\begin{tabular}{lllll}
\hline n-layer thickness $(\mathrm{nm})$ & $\mathrm{V}_{\mathrm{OC}}(\mathrm{V})$ & $\mathrm{J}_{\mathrm{SC}}\left(\mathrm{mA} / \mathrm{cm}^{2}\right)$ & $\mathrm{FF}$ & Efficiency $(\%)$ \\
\hline 0 & 0.32 & 7.25 & 0.41 & 0.94 \\
10 & 0.74 & 9.53 & 0.33 & 2.35 \\
20 & 0.81 & 10.25 & 0.59 & 4.82 \\
30 & 0.83 & 11.05 & 0.59 & 5.36 \\
40 & 0.82 & 10.32 & 0.62 & 5.26 \\
\hline
\end{tabular}

These results suggest that once the layer has reached the critical thickness of $20 \mathrm{~nm}$, the properties cannot be improved much further by increasing the n-layer thickness. Moreover, the PEC characteristics of the $40 \mathrm{~nm}$ sample suggest that if the thickness of the n-layer is increased too much, the charge carriers might not be able to be easily injected into the electrolyte due to the additional resistances, and might prevent possible tunnelling of charge carriers to occur.

When performing the light induced degradation experiments shown in Figure $7 \mathrm{~d}$ ), an additional advantage of this n-layer was found. The performance of the cells measured as solid-state devices degraded up to efficiencies of almost $0 \%$ in $1000 \mathrm{~h}$ of exposure for the samples with thinner n-layer. On the other hand, samples with thicker n-layer have an efficiency change in the order of $30-40 \%$ with respect to the initial value. This suggests that the a-SiC:H absorber layer without an n-layer tends to degrade upon illumination. This could be explained by the mechanism of the Staebler-Wronski effect. ${ }^{[33]}$ When charge carriers are generated in the absorber material but cannot be separated, they will recombine. Upon recombination, energy is released within the absorber material, creating the metastable defects that cause light induced degradation. By introducing efficient means of separating the charge carriers and reducing the recombination inside the absorber material, this effect can be reduced. Thus, the introduction of an n-type nc-SiO $: \mathrm{H}$ improves the optical and electrical characteristics of the photoelectrode, as well as enhancing its stability upon illumination at ambient conditions. Since increasing the thickness of the n-layer further than $20 \mathrm{~nm}$ does not have a big effect on the optical or electrical properties of the photocathode, this thickness has been chosen as the standard for further studies.

To further improve the photocathode, also the light absorption in the absorber layer must be taken into account. Thus, to increase the light absorption in the $\mathrm{p} / \mathrm{i} / \mathrm{n} \mathrm{a}-\mathrm{SiC}: \mathrm{H}$ photocathode, the $\mathrm{i}$-layer thickness can be optimized. Figure 8 shows an increase in short circuit current density with thicker i-layer due to the higher light absorption. Figure $8 \mathrm{a}$ indicates that if the i-layer thickness is as small as $50 \mathrm{~nm}$, extra resistances and possible pinholes may appear, causing shunts and a very poor fill factor. For thicker layers this is not a problem anymore, since the i-layer is then thick enough to maintain a higher homogeneity. This effect is also reflected in the fill factor shown in Table 2. Regarding the optical effects, the photocathodes with i-layers thicker than 150 $\mathrm{nm}$ show a saturation of the current density, display only a slight improvement in absorption in the red part of the spectrum (Figure 8b). However, the solid-state JV measurement shows a lower fill factor for $200 \mathrm{~nm}$ than for $150 \mathrm{~nm}$. Thus, the additional absorption would be compensated by the enhanced recombination due to extra defects introduced, creating a balance between the optical and electrical properties of the layer It is also apparent from the EQE measurements in Figure $8 \mathrm{~b}$ that the EQE in the short wavelength region reduces with an increase of i-layer thickness. This can be explained by the reduced charge carrier collection at the $p$-layer, since the electric field is weakened.
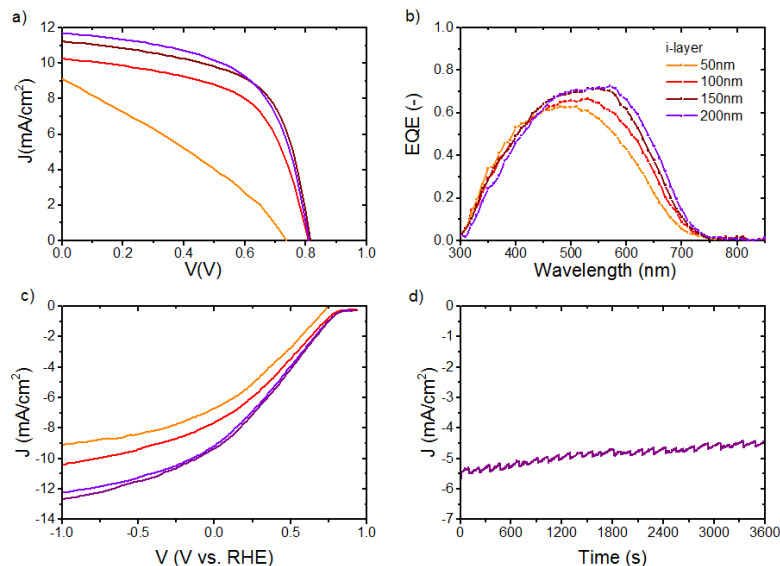

Figure 8. a) Solid state JV curves, b) EQE measurements and c) PEC JV curves of the a-SiC:H photocathodes at different i-layer thicknesses with a $\mathrm{TiO}_{2}$ protective layer and $\mathrm{Pt}$ catalyst, and d) stability test for the $150 \mathrm{~nm}$ a$\mathrm{SiC}: \mathrm{H}$ photocathode with an applied voltage of $0 \mathrm{~V}$ vs. RHE

Table 2. External parameters of the solid state JV characteristics with different i-layer thickness

\begin{tabular}{lllll}
\hline i-layer thickness $(\mathrm{nm})$ & $\mathrm{V}_{\mathrm{OC}}(\mathrm{V})$ & $\mathrm{J}_{\mathrm{SC}}\left(\mathrm{mA} / \mathrm{cm}^{2}\right)$ & $\mathrm{FF}(-)$ & Efficiency $(\%)$ \\
\hline 50 & 0.74 & 9.02 & 0.32 & 2.09 \\
100 & 0.81 & 10.25 & 0.59 & 4.82 \\
150 & 0.82 & 11.21 & 0.60 & 5.58 \\
200 & 0.81 & 11.68 & 0.59 & 5.57 \\
\hline
\end{tabular}

When looking at the PEC performance, the trend again seems to saturate at $150 \mathrm{~nm}$. In this case, the series resistance for both $150 \mathrm{~nm}$ and $200 \mathrm{~nm}$ is the same, indicating that the series resistance in the solution is probably the limiting effect. Since there is not much difference between $150 \mathrm{~nm}$ and $200 \mathrm{~nm}, 150$ $\mathrm{nm}$ was chosen as the optimum layer thickness for this device as it would suffer less from light induced degradation [33] Chronoamperometry measurements were performed on the $\mathrm{p} / \mathrm{i} / \mathrm{n} / \mathrm{TiO}_{2}$ photocathode with an i-layer thickness of $150 \mathrm{~nm}$ to determine its stability in the electrolyte, displayed in Figure 8d). These measurements show that the photocathode can be reasonably stable for more than an hour, with a reduction of the photocurrent of less than $20 \%$. When only considering the solid state degradation upon illumination, the photocathode with 20 $\mathrm{nm}$ n-layer showed a reduction in the short circuit current of about $10 \%$. Thus, it could be assumed that about half of the stability loss is related to the Staebler-Wronski effect, while the other half would be caused by chemical degradation. Although the detailed study of the chemical degradation observed was out of the scope of this paper, literature suggests that it might be related to catalyst detachment. ${ }^{[2]}$ Therefore, it seems that, at least in the first hour, the solid state stability and chemical stability are comparable.

\section{Conclusions}

This paper demonstrates the importance of device design to enhance the separation and collection of charge carriers, and reduce the recombination losses, not only for $\mathrm{PV}$ but also for the PEC field. By introducing an n-doped nanocrystaline silicon oxide (nc-SiO $: H$ ) layer onto an amorphous silicon carbide (a- 
$\mathrm{SiC}: \mathrm{H})$ photocathode, its performance for solar water splitting can be improved. It can highly enhance the internal electric field and charge carrier selectivity of the photocathode, improving the charge carrier separation and collection. In addition, it also protects the photocathode of degradation upon illumination by reducing the $\mathrm{SRH}$ recombination. However, to improve the band alignment with the electrolyte, a $\mathrm{TiO}_{2}$ layer is needed. The minimum thickness of the $\mathrm{n}-\mathrm{SiO}_{\mathrm{x}}: \mathrm{H}$ layer was determined to be $20 \mathrm{~nm}$. To enhance light absorption without affecting the charge collection performance, the optimum absorber a-SiC:H layer thickness of this $\mathrm{p} / \mathrm{i} / \mathrm{n}$ photocathode was found to be $150 \mathrm{~nm}$. Using these specifications, an onset potential of $0.8 \mathrm{~V}$ vs RHE and a current density of $10 \mathrm{~mA} / \mathrm{cm}^{2}$ at $0 \mathrm{~V}$ vs. RHE can be achieved, with a loss in efficiency of only $20 \%$ after $1 \mathrm{~h}$ of operation.

\section{Experimental Section}

Photocathode deposition. The a-SiC:H and nc-SiO $\mathrm{x}: \mathrm{H}$ layers were deposited using Radio Frequency Plasma Enhanced Chemical Vapour Deposition (RFPECVD). Asahi UV-type, consisting of a textured glass with an FTO coating, was used as a substrate. A p/i or $\mathrm{p} / \mathrm{i} / \mathrm{n}$ structure was used, in which the $\mathrm{p}$-type layer was a $10 \mathrm{~nm}$ film of boron doped hydrogenated silicon carbide ((p)a$\mathrm{SiC}: \mathrm{H})$, the i-type layer was a film of intrinsic hydrogenated amorphous silicon carbide ((i)a-SiC:H), and the n-type layer was phosphorous doped nanocrystalline silicon oxide $\left((\mathrm{n}) \mathrm{nc}-\mathrm{SiO}_{\mathrm{x}}: \mathrm{H}\right)$. Unless otherwise stated, the i-type layer was $100 \mathrm{~nm}$ and the n-type layer was $20 \mathrm{~nm}$. The precursor gases used were $\mathrm{SiH}_{4}, \mathrm{CH}_{4}, \mathrm{H}_{2}$ and $\mathrm{CO}_{2}$. Doping of $\mathrm{p}$ and $\mathrm{n}$ layers was realized using the gases $\mathrm{B}_{2} \mathrm{H}_{6}$ and $\mathrm{PH}_{3}$, respectively. Different layers $(p, i, n)$ were deposited in different chambers of an Elettrorava cluster PECVD tool to avoid cross contamination. As a front contact, a $300 \mathrm{~nm}$ Al stripe was deposited on the FTO by electron beam evaporation in a Provac evaporator, and then a silver wire was attached to it using carbon paste.

For some of the PEC measurements, a titanium oxide $\left(\mathrm{TiO}_{2}\right)$ layer of $20 \mathrm{~nm}$ was deposited using an in-house Atomic Layer Deposition (ALD) system located at TU Delft. During deposition, the substrate temperature was $200{ }^{\circ} \mathrm{C}$. Tetrakis (dimethylamino)-titanium (TDMAT) and water were used as precursors for the $\mathrm{Ti}$ and $\mathrm{O}$, respectively. The growth rate was $0.6-0.8 \AA$ per cycle, measured by ellipsometry. The samples were further annealed at $300{ }^{\circ} \mathrm{C}$ for an hour to crystallize the material. Subsequently, a layer of $1 \mathrm{~nm} \mathrm{Pt}$ catalyst was deposited using sputtering with radio frequency $(R F)$ in a PREVAC sputtering tool, with a deposition rate of $0.5-0.6 \AA / s$. This relatively high deposition rate allows the formation of nanostructures, which improve its catalytic activity. [34]

Solid-state characterization techniques. The activation energy of the different layers was determined by measuring the dark conductivity of the laye at different temperatures between 60 and $135^{\circ} \mathrm{C}$, and fitting the results to an Arrhenius plot.

The external quantum efficiency (EQE) represents the percentage of incident photons on the device that produce charge carriers that would be collected. Here, the EQE was measured with an in-house system in the PVMD group TU Delft, consisting of a Xe lamp attached to a monochromator. A Ge calibration diode was used for correcting the spectrum. When measuring EQE a back contact of $200 \mathrm{~nm} \mathrm{Ag}, 30 \mathrm{~nm} \mathrm{Cr}$ and $500 \mathrm{~nm}$ Al was deposited by physical evaporation on the photocathode. This stack enhances reflectivity and ensures the chemical stability of the layer. The short circuit current was obtained by integrating the EQE weighted with the AM1.5 solar spectrum.

The solid state measurements of the JV characteristics were done under a double lamp Class AAA Wacom solar simulator. The temperature at Standard Test Conditions (STC) of $25^{\circ} \mathrm{C}$ was maintained by a Julaboo cooling system integrated in the measurement stage. When measuring solid-state JV curves, a metal back contact was also deposited, defining a cell area of $0.16 \mathrm{~cm}^{2}$. The short circuit current density $\left(\mathrm{J}_{\mathrm{SC}}\right)$ obtained from these measurements was normalized by the $\mathrm{J}_{\mathrm{SC}}$ obtained by integrating the EQE output over the AM1.5 spectrum.

Finally, amorphous silicon (a-Si:H) is known to degrade under illumination due to the Staebler-Wronski effect $[\underline{33]}$, related to metastable defects inside the material. In order to study if a-SiC: $\mathrm{H}$ has a similar behaviour, the a-SiC: $\mathrm{H}$ cells with a back contact were exposed to constant illumination of 1 sun at $25^{\circ} \mathrm{C}$ for $1000 \mathrm{~h}$, and the solid-state JV characteristics of these cells were measured several times during this process. The light-induced degradation is presented as the normalized value of the external parameters with respect to the initial state.
Photoelectrochemical (PEC) characterization techniques. The JV characteristic as a PEC device was measured using an aqueous $0.2 \mathrm{M}$ potassium hydrogen phthalate (Alfa Aesar, 99.99\%) solution at $\mathrm{pH} 4$ as electrolyte. The measurements were carried out with a 3 electrode configuration, as shown in Figure 1, with an $\mathrm{Ag} / \mathrm{AgCl}$ reference electrode (XR300, Radiometer Analytical) and a Pt wire counter electrode. This configuration was chosen to focus on the photocathode performance, independently from the anode behaviour. The solar simulator used was a Newport Sol3A Class AAA. The illumination area in contact with the solution was a $3 \mathrm{~mm}$ radius circle, with a total area of $0.283 \mathrm{~cm}^{2}$. Note that the current densities achieved by this method my vary from the solid-state JV measurements due to differences in the diffused light and inaccuracies on the equipment. The solid-state measurements are considered more reliable when determining current densities, since they have been corrected using the EQE measurements.

To determine the stability in the electrolyte, chronoamperometry measurements were performed, where the current is measured on time at a constant voltage applied. Note that the current density measurements obtained as PEC are less accurate due to internal reflections and diffused light effects within the measurement equipment.

Electrochemical Impedance Spectroscopy (EIS) measurements were performed in the dark on an (n)nc-SiO $: \mathrm{H}$ layer of $100 \mathrm{~nm}$ deposited on Asahi substrate, and on a $100 \mathrm{~nm} \mathrm{TiO}_{2}$ sample in order to determine the flatband position of the relevant interfaces. EIS measurements were also carried out on the full photocathodes consisting of a-SiC:H and a-SiC: $\mathrm{H} / \mathrm{TiO}_{2}$ structures. A Metrohm Autolab potentiostat was used, with a reported measurement error of $\pm 0.2 \%$. ${ }^{[35]}$ Impedance data were collected between $10^{-2}$ $-10^{6} \mathrm{~Hz}$ using a $20 \mathrm{mV}$ amplitude voltage perturbation and analysed with the ZView software (Scribner associates). Finally, to better understand the obtained behaviour, electrical simulations were performed using the SENTAURUS software.

\section{Acknowledgements}

We thank Rene van Swaaij for his helpful comments and insight during the course of this work. This work is part of the research programme of the Foundation for Fundamental Research on Matter (FOM-13CO19), which is part of the Netherlands Organisation for Scientific Research (NWO).

Keywords: Charge carrier injection - Amorphous silicon carbide - Hydrogen $\bullet$ n-type $\mathrm{SiO}_{\mathrm{x}} \cdot \mathrm{TiO}_{2}$ protective layer

[1] H. Ibrahim, A. llinca, J. Perron, Renewable and Sustainable Energy Reviews 2008, 12, 1221-1250.

[2] G. Nicoletti, N. Arcuri, G. Nicoletti, R. Bruno, Energy Conversion and Management 2015, 89, 205-213.

[3] F. F. Abdi, L. Han, A. H. M. Smets, M. Zeman, B. Dam, R. v. d Krol, Nature communications 2013, 4.

[4] Z. Li, W. Luo, M. Zhang, J. Feng, Z. Zou, Energy and Environmental Science 2013, 6, 347-370.

[5] B. A. Pinaud, J. D. Benck, L. C. Seitz, A. J. Forman, Z. Chen, T. G. Deutsch, B. D. James, K. N. Baum, G. N. Baum, S. Ardo, H. Wang, E. Miller, T. F. Jaramillo, Energy and Envirnmental Science 2013, 6, 1983-2002

[6] F. Urbain, V. Smirnov, J.-P. Becker, A. Lambertz, U. Rau, F. Finger, Solar Energy Materials and Solar cells 2015.

[7] M. G. Walter, E. L. Warren, J. R. McKone, S. W. Boettcher, Q. Mi, E. A. Santori, N. S. Lewis, Chem. Rev. 2010, 110, 6446-6473.

[8] A. Fujishima, K. Honda, S. Kikuchi, Journal of Chemical Society Japan 1969, 72, 108-113.

[9] G. K. Mor, K. Shankar, M. Paulose, O. K. Varghese, C. A. Grimes, Nano Letters 2005, 5, 191-195.

[10] Y. J. Hwang, C. Hahn, B. Liu, P. Yang, ACS Nano 2012, 6, 50605069.

[11] P. S. Bassi, Gurudayal, L. H. Wong, J. Barber, Phys. Chem. Chem Phys. 2014, 16, 11834-11842.

[12] H. Dotan, K. Sivula, M. Gratzel, A. Rotschild, S. C. Warren, Energy and Environmental Science 2011, 4, 958-964.

M. Malizia, B. Seger, I. Chorkendorff, P. C. K. Vesborg, Journal of Materials Chemistry A 2014, 2, 6847-6853.

[14] F. F. Abdi, N. Firet, R. van de Krol, Chem Cat Chem 2013, 5, 490 496 
[15] J.-W. Jang, C. Du, Y. Ye, Y. Lin, X. Yao, J. Thorne, E. Liu, G. McMahon, J. Zhhu, A. Javey, J. Guo, D. Wang, Nature communications 2015, 6, 7447 .

[16] J. Oh, T. G. Deutsch, H.-C. Yuan, H. M. Branz, Energy and Environmental Science 2011, 4, 1690-1694.

[17] L. Shen, C. He, J. Qu, S.-M. Lee, A. Kalita, S. B. Cronin, M. P. Stoykovich, J. Yoon, ACS Appl. Mater. Interfaces 2015, 7, 2604326049.

[18] F. Zhu, J. Hu, I. Matulionis, T. Deutsch, N. Gaillard, A. Kunrath, E. Miller, A. Madan, Philosophical magazine 2009, 89, 2723-2739.

[19] L. Han, I. A. Digdaya, T. W. F. Buijs, F. F. Abdi, Z. Huang, R. Liu, B. Dam, M. Zeman, W. A. Smith, A. H. M. Smets, Journal of Materials Chemistry A 2015, 3, 4155-4162.

[20] R. Marschall, Advanced Functional Materials 2014, 24, 2421-2440.

[21] I. A. Digdaya, L. Han, T. W. F. Buijs, M. Zeman, B. Dam, A. H. M. Smets, W. A. Smith.

[22] I. A. Digdaya, P. Perez-Rodriguez, M. Ma, G. W. P. Adhyaksa, E. C. Garnett, A. H. M. Smets, W. A. Smith, Journal of Materials Chemistry A 2016, 4, 6842-6852.

[23] I. A. Digdaya, G. W. Adhyaska, B. J Tzesniewski, E. C. Garnett, W A. Smith, Nature Communications 2017, 8, 15968 .

[24] J. Mandelkorn, J. J.H. Lamneck, in Record of 9th Photovoltaic Specialists Conference, 1972.

[25] M. Gratzel, Inorganic Chemistry 2005, 44, 6841-6851.

[26] V. Smirnov, A. Lambertz, B. Grootoonk, R. Carius, F. Finger, Journal of Non-Crystalline Solids 2012, 358, 1954-1957.
H. H. Pham, L.-W. Wang, Phys. Chem. Chem. Phys. 2015, 17, 541-550.

[28] A. G. Scheuermann, K. W. Kemp, K. Tang, D. Q. Lu, P. F Satterthwaite, T. Ito, C. E. D. Chidsey, P. C. McIntyre, Energy and Environmental Science 2016, 9, 504-516.

[29] I. A. Digdaya, L. Han, T. W. F. Buijs, M. Zeman, B. Dam, A. H. M. Smets, W. A. Smith, Energy and Environmental Science 2015, 8, 1585-1593.

[30] S.-T. Hwang, D. J. You, S. H. Kim, S. Lee, H.-M. Lee, Solar Energy Materials and Solar Cells 2013, 113, 79-84.

[31] K. Gelderman, L. Lee, S. W. Donne, Journal of Chemical Education 2007, 84, 685-688.

[32] V. Demontis, C. Sanna, J. Melskens, R. Santbergen, A. H. M. Smets, A. Damiano, M. Zeman, Journal of Applied Physics 2013 113, 064508. [33] D. L. Staebler, C. R. Wronski, Applied Physics Letters 1977, 31,

[34] E. Slavcheva, I. Radev, G. Topalov, E. Budevski, Electrochemical Acta 2007, 53, 362-368.

[35] M. Autolab, 2018 


\section{Entry for the Table of Contents}

\section{FULL PAPER}

This paper systematically decouples the photovoltaic and catalytic effect for a monolithic device for water splitting for the first time.

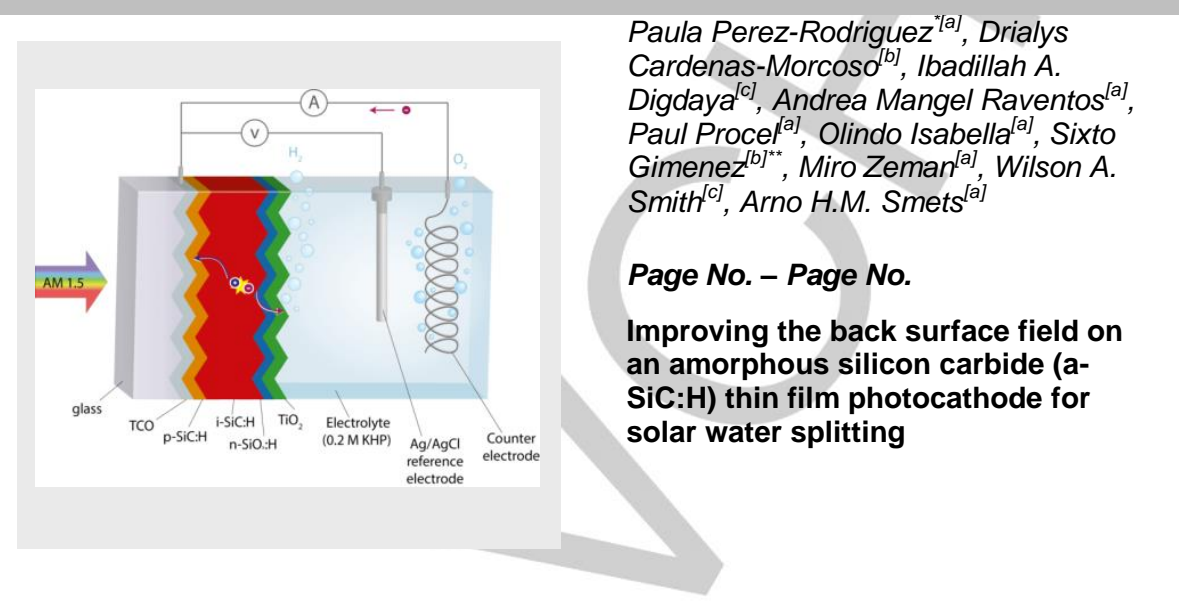

